\title{
MEMÓRIA, GÊNERO E PRÁTICA DOCENTE: ENLACES E DESTAQUES NA FORMAÇÃO DE EDUCADORAS
}

Fernanda Sanjuan de Souza ffsanjuan@gmail.com

Universidade Federal da Bahia (UFBA), Salvador, Bahia, Brasil.

\section{Tereza Cristina Pereira Carvalho} Fagundes

tcrispf@ufba.br

Universidade Federal da Bahia (UFBA), Salvador, Bahia, Brasil.

\section{RESUMO}

Este artigo resulta de um estudo que objetivou evidenciar, em memoriais de formação de estudantes de um curso de licenciatura em Pedagogia, a relação entre o ser mulher e o exercício da prática docente. Foram pesquisadas, em cento e vinte e um memoriais de estudantes de sete municípios baianos, referências a educadoras marcantes em suas histórias de vida, ancoradas nas Epistemologias Feministas que contemplam a valorização das vozes femininas na construção e reconstrução de suas vidas, bem como a subjetividade como base para o entendimento da prática docente. Com a análise de conteúdo processada foi possível evidenciar três categorias de narrativas: referência analítica - quando a menção apareceu seguida por uma tentativa de análise dos métodos e tendências pedagógicas da professora em questão; simples menção a métodos e tendências pedagógicas - quando a educadora mencionada foi sumariamente caracterizada por alguma atividade que desempenhava, porém sem preocupação analítica e apresentação breve - quando nada relevante acerca da prática pedagógica foi referido. Tais resultados apontam para a necessidade de se repensar a orientações para construção de memoriais de formação para minimizar a ênfase em a práticas pedagógicas não reflexivas e críticas que tendem a associar os saberes da docência a ideias do senso comum e a entender as práticas pedagógicas como um conjunto de técnicas não reveladoras de intenções sociais, políticas e culturais mais do que seu significativo papel na formação de educadoras num curso como o de Pedagogia.

PALAVRAS-CHAVE: Memória. Gênero. Prática Docente 


\section{INTRODUÇÃO}

Nos últimos trinta anos, o panorama dos estudos sobre gênero e educação tornou-se notório no Brasil e no Mundo. A publicação do número especial Mulher e Educação, da Revista Educação e Realidade, organizado por Guacira Louro e Eliane Marta Lopes, em 1990, deu a conhecer, no Brasil, as pesquisas que vinham sendo desenvolvidas em consonância com a linha de estudos internacionais, denominada Estudos da Mulher. Nessa linha epistemológica, destaca-se a historiadora Joan Scott, com seu trabalho Gênero: uma categoria útil de análise histórica (1991). Também "[...] a relação entre docência e gênero passou a ser problematizada e a ganhar consistência a ponto de o gênero adquirir estatuto de categoria indispensável aos estudos sobre docência" (NASCIMENTO, 2011, on line) e, portanto, demandar mais estudos fundamentados nesse viés.

Em cursos de formação de educadoras(es), é mister considerar essas categorias desde a definição do currículo até a realização de estudos que promovam a ampliação de saberes na área.

Com esta perspectiva, foi feita uma pesquisa com o objetivo de investigar, nos memoriais de conclusão de curso de graduandas de Pedagogia de uma universidade baiana, referências a educadoras marcantes na história de vida das formandas e suas relações com a prática docente.

Conhecer e vivenciar aspectos da prática docente e suas relações com as questões de gênero, que não costumam ser enfatizados nem nos currículos da formação acadêmica, nem na atuação profissional de educadoras, foi a motivação para esta pesquisa. A metodologia de trabalho foi ancorada nas Epistemologias Feministas pela aposta das pesquisadoras em um fazer científico que contemplasse a expressão da subjetividade como ponto fundante para o entendimento do trabalho profissional das(os) docentes (NÓVOA, 2007), bem como a valorização das vozes femininas na construção e reconstrução de suas histórias de vida.

Até os dias atuais, o curso de Licenciatura em Pedagogia, no Brasil, é majoritariamente feminino porque há, por parte de quem o cursa, a incorporação de uma "[...] crença de ser essa profissão adequada à mulher, por diversos motivos. Tem-se por um lado a vocação construída na dialética entre o que a mulher pensa e o que a sociedade a leva a pensar, constructos associados ao ser mulher, reificados ao longo da história [...]" (FAGUNDES, 2005, p. 45). Fundamentados nesses fatos, boa parte dos estudos sobre gênero têm se centrado nas investigações acerca das implicações sócio-históricas e culturais da atividade docente das mulheres (FAGUNDES, 1999, 2000, 2005; LEMOS, 2011, TEIXEIRA, 2010; WERLE, 2005). Outros(as) pesquisadores(as) se interessam por trabalhar a memória histórica e social a partir das memórias individuais, também conhecidas por histórias de vidas - referencial teórico-metodológico que tem oferecido rico campo de pesquisa em educação, como é possível encontrar na literatura sobre o tema como Passos e Rodrigues (2005), Mendes (2004), Machado (2010), dentre outros.

A difusão de tais estudos pode ser justificada pela potencialidade que eles têm de trazer à luz questões profissionais que podem ser mais bem elucidadas quando contextualizadas com múltiplas esferas do cotidiano. 
[...] os estudos referentes às vidas dos professores podem ajudar-nos a ver o indivíduo em relação com a história do seu tempo, permitindo-nos encarar a interseção da história de vida com a história da sociedade, esclarecendo, assim, escolhas, contingências e opções que se deparam no indivíduo. (GOODSON, 2007, p. 75).

Reconstruir as histórias de vidas de educadoras que se diferenciaram e foram reconhecidas no seu entorno, analisa Passos (2005, p. 9), permite "[...] saber por que elas foram destacadas e se estavam conscientes da relação entre os meios e os fins da sua ação educativa, é uma forma de desvelar sentidos, abordar valores e entender o contexto sociocultural."

Seguindo essa linha, adotamos como referencial teórico-metodológico as Epistemologias Feministas tratadas pelo viés da construção de histórias de vida, escolha justificada por objetivarmos uma maior compreensão sobre a questão de gênero associada à educação e à importância das mulheres educadoras na construção de saberes pedagógicos. Essa expectativa se assemelha às conclusões obtidas nos estudos de referência que mostraram a importância da vida profissional de educadoras, numa perspectiva de gênero - classificação de identidade que conjuga diferentes esferas: a social, a histórica e a subjetiva.

Assim, estruturamos esse artigo com essa introdução, o detalhar da metodologia e a apresentação dos resultados que compõem o item sobre as memorialistas.

\section{O ESTUDO}

A primeira etapa da realização do trabalho, posterior à pesquisa dos referenciais teóricos, foi a identificação dos memoriais de formação ${ }^{1}$ de curso das(os) formandas(os) da turma de 2008, da Licenciatura em Pedagogia, presentes no acervo de material impresso da Universidade estudada. Foram encontrados no acervo e analisados 121 memoriais. Na análise, buscamos identificar se os memoriais tinham indicação de educadoras marcantes na vida das memorialistas, seus principais nomes e se havia referência à influência que essas educadoras teriam exercido no fazer pedagógico das formandas.

Nosso material de análise era composto dos memoriais das(os) formandas(os) dos municípios baianos de ALC - Alcobaça, ALA - Alagoinhas, BEL Belmonte, GUA - Guaratinga, MIR - Mirangaba, NOV - Novo Horizonte e POR Porto Seguro.

A análise criteriosa permitiu identificar características gerais das graduandas que compõem o universo estudado (como sexo, ano de nascimento, realização de estudos anteriores na área da educação, situação econômica da família e necessidade de deslocamento para formação acadêmica) e destacar suas citações referentes às educadoras que mais exerceram influência no seu fazer pedagógico.

Seguindo as identificações supracitadas, fizemos análises quantitativas e qualitativas dos achados. $O$ estudo quantitativo permitiu traçar o perfil do grupo pela frequência das características elencadas pelas formandas. $O$ estudo qualitativo se concentrou nas referências existentes, nas falas das estudantes às 
educadoras marcantes, baseando-nos nas Epistemologias Feministas e no método analítico de Histórias de Vida.

Partindo do referencial metodológico de Análise de Conteúdo, fizemos inferências e interpretações das falas, diferenciando-as e agrupando-as em categorias que serão apresentadas a seguir. Como defende Bardin (1977, p. 177), "Classificar elementos em categorias impõe a investigação do que cada um deles tem em comum com outros. O que vai permitir o seu agrupamento é a parte comum existente entre eles."

\section{AS MEMORIALISTAS}

O grupo estudado foi o de formandas(os) em Pedagogia que escreveram seu Memorial de Formação como Trabalho de Conclusão de Curso, no ano de 2008 , numa universidade baiana - $85 \%$ de mulheres e $15 \%$ de homens - dados estes que reafirmam a tendência de feminização do curso de Pedagogia, iniciada no início do século XIX e que perdura até os dias atuais, como mostram os estudos de Amado (1988) e Fagundes (2005), dentre outros.

Por termos mulheres num percentual marcadamente maior do que o dos homens, optamos por fazer referência ao conjunto do grupo de memorialistas neste artigo, empregando a flexão de gênero de substantivos e adjetivos para o feminino. Desta forma, esse conjunto formado pela maioria de mulheres, apesar da presença de homens, será tratado no feminino.

Ainda considerando as características gerais do grupo analisado, observamos que $86 \%$ das estudantes fizeram magistério antes da graduação em Pedagogia e que são frequentes as referências à importância de estar fazendo a licenciatura para se manterem empregadas na área de Educação, principalmente no setor público, como afirma a graduanda Bel04², 1980:

"Resolvi fazer o vestibular e estudar pedagogia na faculdade para não ter problema de me manter ensinando na escola da cidade."

Tal constatação pode encontrar justificativa nas mudanças ocorridas nas disposições legais para atuar na docência ao longo das últimas décadas. A Lei de Diretrizes e Bases da Educação Nacional (LDB), de 1996 (Lei 9.394/96), no artigo 63 , determina que as docentes devem ter formação em curso Normal Superior, oferecido pelos Institutos Superiores de Educação ou pelas Escolas Normais Superiores; e/ou licenciatura em Pedagogia, oferecida pelas Universidades. A habilitação específica em Magistério, em nível de 20 grau (atual Ensino Médio), feita em instituições que não os Institutos Superiores de Educação ou Escolas Normais Superiores, não é aceita legalmente desde 2008.

Destacamos também, como uma característica notória no universo pesquisado, o fato de $60 \%$ do grupo declarar, de modo direto ou indireto, vir de família com poucos recursos financeiros. Muitas estudantes são da zona rural da cidade-polo onde cursaram a licenciatura. Outro dado relevante é que $17 \%$ afirmam ter precisado se mudar de cidade, sendo o estudo o mote de tal deslocamento. 
Não raro também foram encontradas referências aos deslocamentos pendulares diários, como afirma a depoente Alc07 (197-? ), contemplando a maioria das questões anteriormente descritas:

"[...] nasci na zona rural, vinda de uma família pobre, enfrentei muitas dificuldades, tive que trabalhar muito cedo, ou seja, ainda criança [...] eu e meus irmãos tínhamos muita dificuldade para ir à escola pelo fato de ser muito longe da nossa casa. ĺamos uma semana a cavalo e, a outra, a pé. Assim, os cavalos descansavam e, na semana seguinte, éramos nós quem descansava, porque estávamos com os pés cheios de bolhas de tanto caminhar, pois íamos descalços para a escola, não tínhamos sapatos, mas não passou pela minha cabeça, em nenhum momento, desistir." (ALCO7, mulher, [197-? $\left.\left.?^{3}\right]\right)$.

Tal depoimento evidencia, ainda, a persistência em continuar os estudos, mesmo diante dos problemas econômicos e de deslocamentos.

\section{PROCURANDO SEMELHANÇAS NA DIVERSIDADE}

Esta categoria, como todas as outras, emergiu dos textos autobiográficos das concluintes da licenciatura em Pedagogia sobre memórias que tinham de professoras marcantes nas suas vidas escolares de ciclo básico. Notamos que 53\% das estudantes fizeram uma ou mais referências a professoras que lembram ter tido ao longo da sua história de estudos nesse período. Essas alusões têm naturezas muito diversas, portanto, optamos por agrupá-las em subcategorias para análise dos dados.

Nesse sentido, foram estabelecidas três subcategorias, excludentes entre si,j de menção às professoras, de acordo com o grau de reflexão acerca da atividade docente sugerida no texto:

a) referência analítica - quando a menção aparece seguida por uma tentativa de análise dos métodos e tendências pedagógicas da professora em questão;

b) simples menção a métodos e tendências pedagógicas - quando a professora mencionada é sumariamente caracterizada por alguma atividade que desempenha, porém sem preocupação analítica; e

c) apresentação breve - quando nada relevante acerca da prática pedagógica é referido.

Adicionalmente, mostrou-se relevante a inclusão de uma quarta categoria, não excludente em relação às demais, relacionada à alusão a "atributos físicos e comportamentais das professoras", variável cuja recorrência foi significativa.

\section{REFERÊNCIA ANALÍTICA}

Nessa categoria, foram incluídos textos que contêm comentários sobre as práticas pedagógicas para além da mera citação de atividades desenvolvidas pelas professoras, ou da simples nomeação do método pedagógico empregado por elas. No entanto, esses comentários complementares que, geralmente, têm caráter valorativo, não estão exclusivamente relacionados a saberes e fazeres 
característicos e inerentes à Pedagogia ou não estão acordes com as discussões mais atuais nesse campo científico.

Constatamos que depoimentos de $14 \%$ das estudantes integram esta categoria.

A seguir, destacamos trechos dos memoriais classificados nesse grupo:

“[...] na época em que fiz o magistério não se falava em professor reflexivo. As palavras de Paulo Freire "[...] por isso é que, na formação permanente dos professores, o momento fundamental é o da reflexão crítica sobre a prática [...]" me fazem pensar no aprendizado que tive com os professores que julguei não terem sido bons professores durante o magistério. Hoje os tenho como referência do que não devo fazer nas minhas aulas, como, por exemplo, ler revistas e deixar os alunos ociosos, ou pedir para pintarem desenhos sem nenhum objetivo, apenas para que fiquem quietos, entre outros absurdos. Me recordei de uma professora de Estudos Sociais que nos pediu para fazermos uma pasta com datas comemorativas. Durante um bimestre, a aula se resumiu a pintar desenhos mimeografados para compor a pasta." (GUA25, mulher, 1975).

“[...] a professora A. me castigava bastante e também meus colegas com bolos nas palmas das mãos, usando palmatória de madeira. Os pais achavam que esse era a maneira correta para ensinar a ler e escrever, pois eles foram alfabetizados assim e desconheciam outra maneira de aprender." (MIR12, mulher, 1971).

"Neste tempo ainda se usava a sabatina [...] essa professora adorava esse método, por isso não gostava muito dela. Todos os alunos deveriam estar com a lição e a tabuada na ponta da língua para não levar bolo e ficar de castigo e ainda ser vaiado pelos colegas. Essa metodologia deixou marcas e era exercida com bastante autoridade. Mesmo assim, valeu a pena, pois muita gente queria mais do que ler e escrever, e o método acaba nos obrigando a nos realizar de uma forma ou de outra. Não era a professora que era má, mas, sim, o método aplicado com o apoio dos pais, que em sua grande maioria eram analfabetos e não queriam que os seus filhos fossem condenados a isso." (MIR16, mulher, [197-? $\left.{ }^{4}\right)$.

“[...] a professora I.A. com quem estudei a 3a e a 4a série do EF [Ensino Fundamental], era uma figura respeitada por meus pais, por seus métodos tradicionais que, segundo eles, educavam. Os alunos temiam sua régua e eu tive a dor de senti-la algumas vezes entre as pernas e nas mãos. Ela dava medo em todos os alunos, eu particularmente me esforçava bastante fazendo todas as tarefas, usando fardamento limpinho e completo e ainda o paninho de forrar a carteira, tudo para não cair nas suas garras. Essa professora, além de rigorosa em seus métodos, tinha péssima mania de escolher entre os seus alunos dois ou três para bajular, geralmente aqueles que tinham melhores condições financeiras e nos demais, reguadas e mais reguadas. Ficava horrorizada com tudo aquilo, mas ainda assim quis continuar a estudar com ela, acho que por desafio. Lembro-me de que no momento da leitura, íamos para frente e ela ficava atrás com sua temida régua, e a cada palavra errada, ou uma vírgula atropelada, a régua entrava em ação com tamanha força, que vários colegas chegavam a derramar lágrimas, tendo que, em seguida, sufocá-las. [...] mas para essa professora deixo os meus sinceros agradecimentos, pois ela me ensinou a ser diferente com os meus alunos e a pelo menos tratar a todos igualmente, não excluindo como ela fazia. Agradeço-Ihe também porque passei a me dedicar mais e a prendi muito com isso. (MIR33, mulher, 1982)." 
Depreendemos dos relatos anteriores que as análises variam muito com relação à forma e ao elemento central da reflexão. Nesse contexto, $59 \%$ das produções que compõem essa categoria, o que corresponde a $9 \%$ do universo de estudo, apresentam análises perspectivadas tanto pela aprendizagem acadêmica quanto pela aprendizagem experiencial dos conhecimentos pedagógicos assimilados pelas concluintes. Nesse aspecto, constatamos que esse olhar reflexivo possibilitou às graduandas fazer uma avaliação das ações educativas das professoras citadas, valendo-se de pelo menos um dos vieses do conhecimento pedagógico descrito por Libâneo (2010): análise dos objetivos sociopolíticos gerais e/ou seus reflexos nas formas organizativas e metodológicas dessa ação. Tal olhar pode também ter possibilitado às concluintes perceber o que, nas ações pedagógicas das docentes, favoreceu ou dificultou seus processos de desenvolvimento cognitivo, afetivo e sociocultural quando alunas.

Uma representação dessa avaliação com foco no saber pedagógico são as questões trazidas pela formanda (GUA25 mulher, 1975). Ela ressalta a ausência de objetivos pedagógicos nas atividades desenvolvidas na sala de aula por suas professoras. Segundo a graduanda, apesar de a docente aplicar componentes metodológicos que, aparentemente, parecem participativos (criar as próprias pastas de trabalho para construir o que hoje denominamos portfólio, prática muito em voga), o conteúdo dessa atividade revela que sua finalidade cumpria apenas a função de contenção dos(as) alunos(as), ou seja, era um tipo de entretenimento para evitar mais desgastes por parte da própria professora.

Contrastando com esse tipo de análise mais aprofundada e instrumentalizada para os saberes pedagógicos, observamos que $41 \%$ dos trechos analíticos sobre as docentes, ou $6 \%$ do universo total são comentários que se baseiam mais em conceitos e valorações do senso comum do que em proposições da ciência da Educação, como seria o esperado entre estudantes de Pedagogia.

Esta análise é notória na produção da estudante (MIR16 mulher, 1982), que nos permite depreender que a avaliação do trabalho docente em questão é feita por percepções do senso comum, uma vez que a graduanda se vale exclusivamente do olhar leigo dos pais e mães dos estudantes da comunidade como critério de valoração da conduta da profissional. Ela não coloca em questão, por exemplo, que o senso comum, no final do século $X X$, acate a naturalização de castigos corporais dentro do espaço da sala de aula. Apenas citao sem qualquer problematização, o que, muito embora não fosse requerido na construção memorial, seria de se esperar, levando em consideração que esse tipo de castigo foi vetado pela lei brasileira desde o final do século XIX, como aponta Daniel Lemos (2012).

Os relatos das estudantes (MIR16, mulher, 197-? ${ }^{5}$ ) e (MIR33, mulher, 1982) também evidenciam que o entendimento de conceitos profissionais específicos da pedagogia, por parte dessas estudantes, mostra-se permeável a imprecisões oriundas do senso comum. Nessas falas, cujas ideias são, em maior ou menor intensidade recorrentes no conjunto pesquisado, notamos que, embora se valorem negativamente as escolhas pedagógicas das docentes, há uma tendência à valoração positiva da aprendizagem, normalmente referente à alfabetização, alcançada por esses mesmos métodos. Também é ambígua a avaliação da própria professora: embora seus métodos apareçam caracterizados negativamente, sua 
imagem, como um todo, aparenta estar desvinculada dessas escolhas pedagógicas, pois é referida como "positiva" nos memoriais.

\section{SIMPLES MENÇÃO A MÉTODOS E TENDÊNCIAS PEDAGÓGICAS}

Tal categoria é formada por textos que contêm citações de atividades pedagógicas realizadas pelas docentes e/ou alusão, não seguida de análise ou qualquer outra explicação pormenorizada de tendências pedagógicas orientadoras das práticas docentes.

Constatamos que $22 \%$ das referências pertencem a esse grupo.

"[...] ela era exemplo de ensinamento mesmo com o método tradicional daquele tempo." (ALA08, mulher, 1974).

"A professora M.R. nos colocava um atrás do outro e exigia total silêncio e ainda dizia que 'neste dia ela tinha esquecido tudo' e também usava este momento para punir a sala por alguns momentos de indisciplina." (GUA14, mulher, 1966).

"Lembro da professora F. Que, com seminários, nos avaliava." (GUA23, mulher, 1969).

"Com ela aprendi a ler e escrever através do método da silabação. Nas aulas da professora N., eu não via o tempo passar, pois as aulas eram interessantes e prazerosas." (BELO3, mulher, 1971).

"Foi com a professora M.S. que aprendi a ler e escrever. Me recordo o primeiro dia de aula em que fiz a sabatina, recebi vários bolos de palmatória dos meus colegas, pois eles tinham mais conhecimentos, sendo assim passei a me interessar mais, e quando fiz a alfabetização e a primeira série já estava com 10 anos." (MIR11, mulher, 1980).

Depreendemos dos relatos que as estudantes não problematizam as escolhas dos métodos das professoras. Estes são tratados como meros instrumentos, ou seja, as estudantes não manifestam percebê-los como parte de uma tendência pedagógica reveladora de intencionalidades e significados nas suas mais diversas facetas: no papel da escola, na relação professora-aluno(a), no conceito de aprendizagem, no conjunto de conteúdos e nas suas relações com os métodos de ensino-aprendizagem.

Essa constatação nos dá indícios de que as formandas, ao rememorarem o trabalho das suas professoras de outrora, não o fazem do ponto de vista de futuras pedagogas, e sim, do lugar de estudantes exógenas à área de educação. Tal fato corrobora achados da autora Pimenta $(2002$, p.21) que, analisando a formação da identidade docente, afirma que é recorrente que pessoas que cursaram o magistério no ensino médio não se identifiquem como professores(as), pois "[...] olham o ser professor e a escola do ponto de vista do ser aluno." A autora enfatiza que, partindo desse panorama, um dos desafios dos cursos de formação deve ser o de colaborar no processo de consolidação da percepção dos papéis e funções profissionais das docentes.

De um modo geral, nos relatos das memorialistas, as referências aos trabalhos pedagógicos realizados pelas docentes são alusões aos métodos e/ou atividades realizadas. Tal fato pode demonstrar que as concluintes deram mais 
ênfase às reflexões sobre métodos didáticos e menos sobre Pedagogia nos seus aspectos amplos, sinal de que a docência pode estar sendo percebida muito mais como uma técnica do que como uma atividade fundamentada em conhecimentos científicos provenientes da teoria e da prática.

Essa tendência de perceber a prática docente como atividade instrumental e tecnicista sem intencionalidade emancipatória deriva de concepções técnicocientíficas da educação, que estiveram amplamente difundidas a partir de 1968. Atualmente, devido às contribuições de diversos pensadores da educação brasileira como Demerval Saviani, Moacir Gadotti, José Carlos Libâneo e Selma Pimenta, as ciências da educação têm firmado novas tendências como a críticoemancipatória. Essa corrente de pensamento traz uma nova tônica às práticas docentes porque propõe que as docentes reflitam sobre suas próprias práticas (ou de seus colegas profissionais), integrando-as de modo dialético com as teorias para produzir saberes científicos e para fortalecer a imagem do profissional docente como intelectual em contínuo processo de formação (PIMENTA, 2002, p. 28-29).

A defesa das práticas docentes articuladas com a teoria é discutida no âmbito internacional por Tardif (2003) e por Houssaye (2004), autores que sugerem que a prática e a teoria pedagógicas se interpenetrem e se modifiquem mutuamente nas formações docentes. Nesse sentido, os autores brasileiros Franco, Libâneo e Pimenta (2007) defendem a constante motivação da práxis educativa, saber fazer reflexivo que desvela as intencionalidades político-sociais das práticas educativas, através das articulações entre teoria e prática pedagógica.

Levando em consideração que a maioria das concluintes está aprimorando suas formações para a docência, saindo da formação em segundo grau em magistério para a formação superior, e que a tendência defendida para os cursos de licenciatura em Pedagogia, como referimos anteriormente é equacionar teoria e prática, consideramos que, embora não fosse obrigatória a apresentação de uma investigação crítica sobre as práticas pedagógicas das docentes citadas, seria um importante sinal de êxito na construção de práxis educativas, relatos que transpusessem as meras citações dos métodos empregados e que apresentassem análises mais globais e aprofundadas sobre os objetivos intrínsecos às práticas relatadas.

\section{APRESENTAÇÃO BREVE}

Essa categoria reúne relatos que apenas citam o nome da profissional educadora que marcou a história de vida das memorialistas. Oferece alguma descrição geral, como a cidade e/ou escola onde a docente ensinava, e/ou alguma outra informação complementar de natureza não pedagógica.

Encontramos $26 \%$ de referências a docentes que se enquadram nesta categoria, exemplificadas nas falas a seguir:

"[...] a professora DPR foi minha professora na primeira série e uma das primeiras professoras que atuaram no município de Porto Seguro." (PORO1, 
"Não fui bem alfabetizada, porém, na primeira série com a professora A.F., fui melhorando, pois ela passava conteúdos e eu conseguia ler e escrever alguma coisa." (MIR16, mulher, 1976).

"A escola Zaira Dias do Carmo Levenhagem recebeu esse nome em homenagem à primeira professora com curso de magistério a lecionar nessa localidade, ela chegou aqui no ano de 1996, nascida em Ibiaporã, Mundo Novo-BA, estudou e formou-se na cidade de Ponte Nova, atual Wagner." (NOV02, mulher, 1977).

Percebemos que, a despeito de apresentarem algumas professoras como uma importante personalidade para as cidades, posto que elas pertenceram a um grupo de pioneiras nas localidades, as memorialistas não aprofundam a referência ao fato com novas informações ou análise sobre elas. Além disso, não fazem nenhum comentário sobre os trabalhos pedagógicos desenvolvidos pelas educadoras citadas, apesar de terem tido contato com os fazeres pedagógicos delas, ainda que na condição de estudantes.

Constatamos também que, nos memoriais destas estudantes, as referências a estas professoras se esgotam nesses comentários.

\section{MENÇÃO A ATRIBUTOS FÍSICOS E/OU COMPORTAMENTAIS DAS PROFESSORAS}

Os tipos de atributos físicos mencionados foram menções à cor da pele, cabelos e olhos, à estatura das profissionais e/ou comentários sobre seu vestuário. Os atributos comportamentais referiram-se às características das professoras em suas relações interpessoais: alusões à docilidade, afabilidade, delicadeza, disponibilidade, dedicação, empenho, rigidez, exigência e severidade.

Nesta categoria, sendo a única referência feita pelas memorialistas a educadoras marcantes, encontram-se $25 \%$ das alusões analisadas. Esse tipo de menção aos atributos físicos e comportamentais associados a outras que apontam métodos e atividades desenvolvidas (explicadas na categoria 3) perfaz o total de $13 \%$ das referências.

A seguir, selecionamos alguns trechos que ilustram a categoria:

"No segundo ano na escola, minha professora era muito calma. Uma moça branca, pequena e magra, chamada S." (ALCO8, mulher, 1974).

"[...] tive a felicidade de, na 2 a série, ter a mesma professora do ano anterior. Ela era muito enérgica, mas sempre carinhosa [...] ainda a vejo pela rua." (NOV01, mulher, 1971).

"[...] a professora I. A. era tão rígida que até nas ruas fazia medo, pois nos mandava ir para casa." (MIR18, mulher, 1976).

"Comecei meus estudos aos 7 anos na escola Prof. Rômulo Galvão, com a professora C. F. B. Apesar de ser leiga, ensinava-nos com bastante compromisso. Na medida do possível, ensinava-nos com qualidade, pois amava o que fazia. Com ela aprendi as letras do alfabeto, formar classes silábicas e formar pequenas palavras." (MIR39, homem, 1975).

"[...] era a professora leiga que lecionava para as crianças vizinhas. Eu, apesar de muito pequena, adorava brincar de estudar e observava a forma como ela ensinava. Ela era muito paciente e bondosa com todos." (GUA16, mulher, 1970). 
"A professora L. Foi mais do que uma professora. Ensinou-me a ler e escrever, cuidou de mim como uma segunda mãe, abraçou-me quando chorei, deu-me segurança quando tive medo de pular corda, foi minha amiga, um exemplo de afeto, de amor ao aluno $e$ às suas particularidades"." (GUA22, homem, 1975).

Em todos os memoriais citados anteriormente, as referências que as graduandas fazem às docentes se esgotam nesses comentários. Os relatos indicam uma possível associação da figura da profissional com a figura da mulhermãe, que se apresenta acolhedora, carinhosa e disponível, quando há representações de afeto. Nos relatos de desafetos, aparece geralmente a mulherbruxa - aquela que inspira medo. Em ambos os casos, notamos que a referência à lembrança das profissionais não as personifica pelas características dos seus trabalhos: a imagem que surge é a de uma "mulher-padrão", sem características vinculadas diretamente aos seus perfis profissionais ou até mesmo subjetivamente individualizadas. A análise de Perrot (1989) fornece-nos uma linha de interpretação possível para essa constatação:

Ela [a observação das mulheres] diz respeito mais aos discursos que às práticas. Ela se detém pouco sobre as mulheres singulares, desprovidas de existência, e mais sobre "a mulher", entidade coletiva e abstrata à qual se atribuem as características habituais. Sobre elas não há uma verdadeira pesquisa, apenas a constatação de seu eventual deslocamento para fora dos padrões que lhes foram reservados. (PERROT, 1989, p. 11).

O modelo homogêneo de mulher, que tem caráter extremamente ambíguo, porque, ao passo que não se verifica completamente em nenhuma mulher em particular, guia as representações sociais que podem nortear caminhos pessoais, como as escolhas profissionais, é endossado pela ideia de uma relação biologicamente natural entre os sexos e as características comportamentais. Em estudo feito anteriormente, depreendemos das análises relativas a esta situação que a escolha da profissão docente pelas mulheres resulte de uma "[...] incorporação da crença de ser uma profissão adequada à mulher pelos constructos sociais atribuídos a esse sexo: ser dócil, maternal, paciente, bondosa, cuidadora e servil." (FAGUNDES, 2005, p. 45).

Essa ideia de atrelamento do sexo feminino às habilidades para promover a socialização das crianças criou um nicho profissional para as mulheres, garantindo-lhes empregos em profissões que, na prática, são tidas como prolongamentos das suas funções domésticas de cuidado dos(as) filhos(as), de outras crianças e familiares, como é a profissão docente.

Nos relatos das memorialistas, percebemos que ideia de maternagem associada a esta profissão aparece nas frequentes adjetivações das educadoras como uma tentativa de caracterização dos seus trabalhos.

Se, por um lado, a vinculação da maternagem ao magistério foi importante por garantir um nicho de mercado às mulheres, facilitando-lhes a participação na vida econômica da família e a criação de um papel de menor submissão na perspectiva geracional por parte delas; por outro, facilitou a criação e manutenção da proletarização do trabalho docente e da desintelectualização da formação para a docência.

Em um sistema de retroalimentação, tanto a vinculação das habilidades femininas à carreira docente - fato que encontrou eco no discurso de vocação 
para a docência difundido pela Igreja Católica, grande responsável pela escolarização das crianças até o final do século XIX -, quanto o processo de proletarização da docência, com a tomada do controle da educação pelo Estado supostamente leigo, são fatos que criaram e mantiveram a feminilização do trabalho docente.

É premente destacar que, embora as estruturas sociopolíticas e econômicas tenham se transformado de modo tão acentuado ao longo dos últimos três séculos, tendo o controle da educação passado da Igreja para o Estado liberal, o sexo dominante entre o público das carreiras de formação docente não foi alterado de modo significativo e esse fato continua sendo tratado de modo dissimuladamente "neutro". Ou seja, em educação, em que pese haver uma maioria de mulheres atuando, não têm sido feitas flexões de gênero ao considerá-las e a categoria segue sendo tratada (tanto externamente como internamente) pela ótica da dominação masculina - conceito discutido por Bourdieu (2010) ao longo de toda sua obra A Dominação Masculina, publicada pela primeira vez em 1998, posto que os "[...] estudos sobre mulher raramente são incorporados à pesquisa educacional. Ao mesmo tempo, os estudos sobre mulher voltaram-se muito pouco para a área da Educação." (AMADO; BRUSCHINI, 1988, p. 4).

\section{CONSIDERAÇÕES FINAIS}

Depreendemos deste estudo que a maior parte das concluintes (53\%) fez alusão a alguma professora que teve durante a trajetória escolar na educação básica. Entre elas, apenas uma pequena parte (9\%) apresentou análises perspectivadas pela teoria pedagógica e/ou pela práxis pedagógica. Consideramos que esse número pode ser revelador de um suposto distanciamento entre a prática e a teoria nos estudos universitários da licenciatura em Pedagogia, havendo tendência a se considerar a teoria desimportante ou pouco adequada às situações práticas - o que aponta a necessidade de futuros estudos que aprofundem e elucidem mais o tema.

Consideramos que, sendo a universidade um lócus de motivação de práticas investigativas sobre atuação docente, é preciso que se repensem coletivamente dentro dessas instituições, as orientações e/ou a validade dos métodos de produção de trabalhos acadêmicos baseados em histórias de vida.

O mote dessa revisão deve ser investigar uma maneira de construir tais produções, de modo que elas passem a conter em maior medida, de fato, reflexões críticas fundadas em memórias da vida escolar, contribuindo para motivar, assim, escolhas de práticas profissionais ancoradas em práticas refletidas e ressignificadas.

Não condenamos as manifestações das subjetividades nos memoriais autobiográficos, ao contrário, concordamos com o que propõe o estudioso dessas produções, Nóvoa (2003), sobre a necessidade de entendermos melhor a história de vida das professoras como ponto fundante dos seus trabalhos pedagógicos. Por outro lado, entendemos que referências às histórias de vida feitas por pedagogas(os) não devem se limitar a pontos exclusivamente subjetivos, nos quais não se encontram relações claras com os saberes das ciências da educação. Isso porque acreditamos que referências ancoradas no 
conhecimento científico tendem a contribuir mais efetivamente para o seu constante processo de desenvolvimento, baseado nas práticas das mais importantes agentes de tal ciência: as docentes.

Entendemos que as análises de práticas pedagógicas feitas pelas formandas em Pedagogia devem ser mais reveladoras de intenções sociopolíticas, ancoradas nas tendências filosóficas da Pedagogia, e que as referências a características físicas e comportamentais das educadoras que consideraram marcantes, como única ou principal forma de lembrança dessas profissionais, devem ser desencorajadas, pois impulsionam discursos dominantes machistas e distanciados de seu real papel formativo.

Concluímos que as referências feitas por parte de memorialistas a práticas pedagógicas não reflexivas e críticas podem associar os saberes da docência a ideias do senso comum, que entendem as práticas pedagógicas como um conjunto de técnicas não reveladoras de intenções sociais, políticas e culturais mais do que seu significativo papel na formação de educadoras num curso como o de Pedagogia.

Assim sendo, estas menções podem contribuir para o enfraquecimento dos movimentos de consolidação da Pedagogia como lócus de produção científica, baseada na práxis docente, que se opõe às construções e perpetuações de ideias sociais dominantes, como, por exemplo, as diversas formas de dominação, entre elas a masculina. 


\title{
MEMORY, GENDER AND TEACHING PRACTICE: LINKS AND DESTINATIONS IN THE EDUCATION TRAINING
}

\begin{abstract}
This article is the result of a study that sought to prove the relationship between being a woman and the teaching practice analysing memorials of students of a degree in pedagogy. References of outstanding women educators were searched in 120 student's memorials from 7 Bahia municipalities considering Feminist Epistemologies that include appreciation of women's voice in building and rebuilding their lives, and subjectivity working as the basis for the teaching practice understanding. Analysing all content, it was possible to the following narratives categories: analytical reference - when the mention appeared followed by an attempt to analyse methods and pedagogical tendencies of the teacher; simple mention of methods and pedagogical tendencies - when the educator mentioned was briefly characterized by some performed activity, but without analytical concern; and brief presentation - when nothing relevant about pedagogical practice was mentioned. These results indicate a necessity of rethink the guidelines for the construction of training memorials in order to minimize the emphasis on not reflective and critical pedagogical practices. These methods tend to associate teaching knowledge with common sense ideas and to understand pedagogical practices as non-revealing techniques of social, political and cultural intentions rather than their significant role in the educators training in a course such as Pedagogy.
\end{abstract}

KEYWORDS: Memory. Gender. Teaching Practice. 
1 Os memoriais são trabalhos acadêmicos de conclusão de curso na licenciatura em Pedagogia desta Faculdade, exigidos como pre requisito para a concessão de diploma.

2 De acordo com as normas éticas das pesquisas científicas, as referências aos nomes das formandas não serão diretas. Optamos por representá-los através de códigos que correspondem à cidade onde está localizado o polo da faculdade da estudante. Posteriormente ao código, aparecerá a data de nascimento declarada no memorial. Nos casos em que não houver menção a tal data, indicaremos a ausência da informação.

3 Registros como (197-?) significam que sabemos ser a depoente dos anos 1970, mas não tivemos registro efetivo do ano dessa década.

4 Idem a nota de rodapé 2.

5 Idem a nota de rodapé 2

\section{REFERÊNCIAS}

BARDIN, Laurence. Análise de Conteúdo. Lisboa: Edições 70, 1977

BOURDIEU, Pierre. A dominação masculina. 9. Ed. Rio de Janeiro: Bertrand Brasil, 2010.

BRASIL. Lei n.9.394, de 20 de novembro de 1996. Estabelece as diretrizes e bases da Educação Nacional. Diário Oficial [da República Federativa do Brasil], Brasília, DF. Ano CXXXIV, n.248, de 23 dez. 1996, p.27.833-27.841.

BRUSCHINI, Cristina; AMADO, Tina. Estudos sobre Mulher e Educação: algumas questões sobre o Magistério. Caderno de Pesquisa, São Paulo, 1988. Disponível em:

<http://www.histedbr.fae.unicamp.br/acer_histedbr/seminario/seminario8/_file s/Ufg25y3D.doc >. Acesso em: 19 abr. 2016.

FAGUNDES, Tereza Cristina Pereira Carvalho. Quem dita as regras? A questão do pequeno poder das mulheres. Revista Brasileira de Sexualidade Humana, São Paulo, v.11, n.2, p.181-192, 2000.

FAGUNDES, Tereza Cristina Pereira Carvalho. Mulher e Pedagogia: um vínculo resignificado. Salvador: Helvécia, 2005.

FRANCO, Maria A. S.; LIBÂNEO, José Carlos; PIMENTA, Selma. G. Elementos para a 
Pesquisa, v.37, n.130, p.63-97, janeiro/abril, 2007. Disponível em: <http://www.scielo.br/pdf/cp/v37n130/05.pdf>. Acesso em: 19 abr. 2016.

GOODSON, Ivor. Dar voz ao professor: as histórias de vida de professores e o seu desenvolvimento profissional. In: NÓVOA, António (Org.). Vidas de Professores. Porto: Porto Editora, 2.ed, 2007. P.63-78.

HOUSSAYE, Jean. Pedagogia: justiça para uma causa perdida? In: HOUSSAYE, Jean, SOETARD, Michel; HAMELINE, Daniel e FABRE, Michel. Manifesto a favor dos pedagogos. Porto Alegre: ArtMed, 2004.

LEMOS, Daniel Cavalcanti de Albuquerque. Os cinco olhos do diabo: os castigos corporais nas escolas do século XIX. Educ. Real. Porto Alegre , v.37, n. 2, August $2012 . \quad$ Disponível em: <http://www.scielo.br/scielo.php?script=sci_arttext\&pid=S217562362012000200016\&lng=en\&nrm=iso>. Acesso em: 19 abr. 2016.

LEMOS, Greissy Leoncio Reis. A Escola Normal na Bahia e a Educação Feminina. In: Jornada de história, sociedade e educação no brasil, X, 2011, UESB. Disponível em: <http://www.histedbr.fae.unicamp.br/acer_histedbr/jornada/jornada10/_files/z Rq4aLpK.pdf>. Acesso em: 19 abr. 2016.

LIBÂNEO, José Carlos. Pedagogia e pedagogos, para quê? 12.ed. São Paulo: Cortez, 2010.

MACHADO, Antônio Roberto Seixas da Cruz. Mestras do Sertão: a carreira de mulheres formadas pela escolar Normal de Feira de Santana entre 1930 e 1949. In: MACHADO, C. J. S. (Org.). Gêneros e práticas culturais - Desafios e saberes interdisciplinares. Campina Grande: EDUEPB, 2010.p 195-218. Disponível em: <http://books.scielo.org>. Acesso em: 19 abr. 2016.

MENDES, Geísa Flores. Luzes do saber aos Sertões: memória e representações da Escola Normal de Vitória da Conquista. Edições UESB. Vitória da Conquista, 2004.

NASCIMENTO, Cecília Vieira do, Mulheres e Docência: Parceria Revisitada. Anais VI Congresso Brasileiro da História da Educação. UFMG, Belo Horizonte, 2011. Disponível em <www.sbhe.org.br/novo/congressos/cbhe6/anais_vi_cbhe/conteudo/file/677.do c.> Acesso em: 19 dez. 2016. 
NÓVOA, António. Os Professores e as histórias das suas vidas. In: NÓVOA, António (org). Vidas de Professores. Porto: Porto Editora, 2.ed, 2007. p.11-30.

NÓVOA, António. Currículo e Docência: a Pessoa, a Partilha, a Prudência. 1o Colóquio Internacional de Políticas Curriculares, 2003. Disponível em: <http://repositorio.ul.pt/bitstream/10451/4816/1/8575161121_1_11.pdf. > Acesso em: 19 abr. 2016.

PASSOS, Elizete; Amélia Rodrigues. Coleção Educadoras Baianas. Salvador: Edufba, 2005.

PERROT, Michelle. Práticas da Memória Feminina. Revista Brasileira de História. v.9, n.18, agosto-setembro, 1989, São Paulo.

PIMENTA, Selma Garrido. Formação de professores: identidade e saberes da docência. P.15-34. In: PIMENTA, Selma Garrido (Org.). Saberes pedagógicos e atividade docente. 3.ed. São Paulo: Cortez, 2002.

TARDIF, Maurice. Saberes docentes e Formação profissional. 3.ed. Petrópolis: Vozes, 2003.

TEIXEIRA, Adla Betsaida M. Magistério do gênero: impactos da vida de discentes e docentes. In:MACHADO, C. J. S.; SANTIAGO, I. M. F.L.; NUNES, M. L. S. (Org.). Gêneros e práticas culturais: desafios históricos e saberes interdisciplinares [online]. Campina Grande: EDUEPB, 2010. p.35-49. Disponível em: <http://books.scielo.org>. Acesso em: 19 abr. 2016.

WERLE, Flávia Obino Corrêa. Práticas de gestão e feminização do magistério. Cad. Pesquisa. São Paulo, v.35, n.126, December 2005. 
Recebido: 28 de outubro de 2016.

Aprovado: 29 de dezembro de 2016.

Como citar:

SOUZA, Fernanda Sanjuan; FAGUNDES, Tereza Cristina Pereira Carvalho. Memória, gênero e prática docente: enlaces e destaques na formação de educadoras. Cad. Gên. Tecnol., Curitiba, v.9, n. 34, p. 23-40, jul./dez. 2016.

Correspondência:

Tereza Cristina Pereira Carvalho Fagundes

Rua Érico Veríssimo, 199. ed. Neo Itaigara Life Apto.603, Salvador, Bahia. CEP: 41815-340.

Direito autoral: Este artigo está licenciado sob os termos da Licença Creative Commons Atribuição 4.0 Internacional.

(c) 